\section{Haloperidol Use in Acute Traumatic Brain Injury: A Safety Analysis}

\section{Abstract}

Background: The association of delirium with poor outcomes creates a complex picture in traumatic brain injury patients by exacerbating an already increased risk for neurobehavioral sequelae. Haloperidol is commonly used for agitation and delirium; however, adverse events are concerns associated with its use in traumatic brain injury patients. The objective of this study was to assess the safety of haloperidol for the management of agitation and delirium in acute traumatic brain injury.

Methods: A retrospective cohort study was conducted of adult ICU patients admitted from January 2007 to October 2009 with traumatic brain injury and admission Glasgow Coma Score $\leq 12$. Incidence of complications (seizures, neuroleptic malignant syndrome, QTc prolongation, extrapyramidal symptoms, hematologic disturbances) and haloperidol prescribing patters were assessed.

Results: A total of 101 patients were included ( 56 non-haloperidol, 45 haloperidol). There was no difference in types of brain injury. Haloperidol was initiated on average day 8 of admission, and the median daily dose was $9 \mathrm{mg}$ for a median duration of 4 days. The haloperidol group received more analgesics (morphine equivalents) [714 vs. $252 \mathrm{mg}, \mathrm{p}<0.001$ ], and more patients in the haloperidol group received benzodiazepines compared to non-haloperidol group [ $98 \%$ vs. $79 \%$, $p=0.005]$. There was no significant increase in adverse events associated with haloperidol use. Patients in the haloperidol group who developed complications received a higher mean daily dose [ $p=0.013]$. There was no difference in length of mechanical ventilation but the haloperidol group had a longer hospital length of stay.

Conclusion: Treatment of agitation and delirium with haloperidol in acute traumatic brain injury patients is not associated with an increased incidence of complications.

Keywords: Agitation; Delirium; Traumatic brain injury; Haloperidol

\section{Rebecca L Anderson", Kara L Birrer ${ }^{2}$ and Xi Liu-DeRyke ${ }^{3}$}

\author{
1 Lakeland Regional Health, Department \\ of Pharmacy, USA \\ 2 Orlando Regional Medical Center, \\ Department of Pharmacy, USA \\ 3 Florida Hospital, Department of \\ Pharmacy, USA
}

Corresponding authors:

Rebecca L Anderson

Xi Liu-DeRyke
” rebecca.anderson@myLRH.org xi.liu@flhosp.org

PharmD, BCPS, Lakeland Regional Health, Department of Pharmacy, 1324 Lakeland Hills Boulevard, Lakeland, FL 33805, USA.

Pharm D, FCCM, Florida Hospital, Department of Pharmacy, 601 E Rollins Street Orlando, FL 32803, USA.

Tel: 8636871100

Citation: Anderson RL, Birrer KL, Liu-DeRyke $X$. Haloperidol Use in Acute Traumatic Brain Injury: A Safety Analysis. J Intensive \& Crit Care 2016, 2:2.

\section{Background}

Recognition of delirium in the intensive care unit (ICU) and its impact on hospitalization, short-term and long-term outcomes has gained increased awareness in the past decade [1]. The management of delirium is more complicated in patients with traumatic brain injuries (TBI) due to the injury-associated increased risk for neurobehavioral sequelae, including agitation, aggression, and disinhibition [2].
Early recognition and management of delirium is necessary due to the associated morbidity and mortality. It is important to use an agent that is safe for the management of agitation and delirium in the ICU. Haloperidol is a commonly used neuroleptic agent for the management of agitation and delirium in critically ill patients. Haloperidol inhibits dopamine receptors (D2) in the mesolimbic system, which regulates feelings of reward, motivation, and reinforcement [3]. There is concern with the use of haloperidol in TBI patients due to its adverse event profile including neuroleptic 
malignant syndrome (NMS), lowered seizure threshold, and impaired long-term cognitive recovery. NMS is thought to be caused by reduced central dopamine neurotransmission [2]. This is significant in TBI patients because they have decreased dopamine transmission at baseline which may be further exacerbated by haloperidol inhibition. The incidence of NMS varies from 0.02 to $12.2 \%$ based on patient population, with an unknown frequency in TBI patients [2]. TBI patients are also at an increased risk of post-traumatic seizures which can worsen brain injury and haloperidol can exacerbate this risk by lowering the seizure threshold $[3,4]$. Haloperidol may also prolong the length of posttraumatic amnesia, extend the time to return of cognitive function, and increase behavioral and cognitive deficits in TBI patients [2].

Increased awareness of delirium in the ICU has resulted in an increased use of haloperidol. Additional information is needed due to the limited literature available concerning the safety and efficacy of haloperidol in critically ill TBI patients. The purpose of this study was to assess the safety of haloperidol for the treatment of agitation or delirium in patients with acute TBI.

\section{Methods}

This retrospective cohort study was conducted at a Level I trauma center and was approved by the Institutional Review Board. Consecutive TBI patients admitted to the ICU between January 2007 and October 2009 were identified using ICD-9 codes. Patients who were 18 years of age or older and had an admission Glasgow Coma Score (GCS) of 12 or less were retained initially for the study. Those excluded had isolated skull fractures on computed tomography (CT) scan, expired within 72 hours of admission, were actively going through alcohol withdrawal, had a diagnosis of Parkinson's disease, or had a home medication that included an antipsychotic or mood stabilizer. Patients were stratified into two groups, those who received haloperidol and those who did not receive haloperidol during their hospital stay.

Pertinent data were retrieved from the hospital electronic medical record. Demographics collected included age, gender, race, and past medical. Type of TBI, extracranial injuries, GCS, Abbreviated Injury Scale (AIS) Head score, and Injury Severity Score (ISS) were recorded. Concurrent use of sedatives, analgesics, and quetiapine were reviewed. Sedatives were converted to midazolam equivalents and analgesics were converted to morphine equivalents [5].

The primary outcomes were to describe the incidence of complications and the prescribing patterns associated with the use of haloperidol in acute TBI patients. Five complications were assessed during the entire hospital stay including seizures, NMS, QT prolongation, extrapyramidal symptoms (EPS), and hematologic disturbances. The presence of seizures was determined by documentation of occurrence and/or results of an electroencephalography (EEG) if available. NMS was characterized by the development of hyperthermia, severe extrapyramidal dysfunction, alterations in consciousness, altered mental status, and/or autonomic instability [2]. Symptoms of NMS also include an increased serum creatine kinase (CK), acute renal failure, and leukocytosis (WBC $\geq 10,500 / \mathrm{mm}^{3}$ ) [3]. The presence of NMS was determined by documentation provided in the medical chart. The QT interval (QT interval corrected for heart rate) is considered at increased risk for prolongation if $>430 \mathrm{msec}$ for men and $>$ $450 \mathrm{msec}$ for women and prolonged if $>450 \mathrm{msec}$ for men and $>470 \mathrm{msec}$ for women [6]. QT prolongation was determined by documentation in the medical chart and/or the results of an electrocardiogram (ECG) if available. EPS was defined by the presence of Parkinson-like symptoms, akathisia, and/or dystonia and was determined by documentation available from the medical chart. Hematologic disturbances [leukopenia (WBC $\leq 4,000 / \mathrm{mm}^{3}$ ) and/or neutropenia (neutrophils < 40.3\%)] were determined by complete blood counts (CBC) drawn during haloperidol treatment as compared to baseline prior to haloperidol initiation. The prescribing practice patterns of haloperidol use included total dose, average daily dose, total number of haloperidol doses, and duration of haloperidol treatment. Clinical outcome data were assessed including ICU and hospital length of stay (LOS), number of days on mechanical ventilation (MV), and discharge disposition.

Normally distributed data were assessed using Student's t-test. For non-parametric testing, the Mann-Whitney $U$ test was performed. Dichotomous variables were tested using Pearson's Chi-square or Fisher exact test. A $p$-value of $<0.05$ was used to determine statistical significance. A logistic regression analysis was performed to identify independent risk factors associated with the development of complications. All statistical analyses were performed with Microsoft Excel for Windows and SPSS for Windows (version 16.0; SPSS, Inc., Chicago IL).

\section{Results}

A total of 309 TBI patients admitted from January 2007 to October 2009 were screened for inclusion. Eighty-two patients were excluded due to isolated skull fractures on CT scan. Of the 227 patients with a CT scan confirmed TBI, 126 patients were excluded: 100 expired within 72 hours, 11 were going through alcohol withdrawal, 7 had GCS $>12,5$ had home medications that included antipsychotics, 2 charts could not be accessed, and 1 had Parkinson's disease. A total of 101 patients were retained for data analysis: 56 in the non-haloperidol group and 45 in the haloperidol group.

\section{Demographics and clinical outcomes}

There were few differences in baseline demographic characteristics between the two groups (Table 1). Patients in the haloperidol group were younger than those in the non-haloperidol group. The haloperidol group had a higher median ISS score. There were no differences in the type of TBI, with the majority in both groups diagnosed with a traumatic subarachnoid hemorrhage (SAH). Over $70 \%$ of patients had concurrent systemic injuries which may have necessitated the use of analgesics or benzodiazepines.

\section{Haloperidol usage and concomitant medications}

Haloperidol was initiated approximately 8 (4-17) days following patient's admission. Patients in the haloperidol group received a median daily dose of 9 (5-14) mg for duration of 4 (1-7) days. The median total dose received throughout the hospital stay was 35 (10-83) mg. A majority of patients received intravenous (IV) 
Table 1 Baseline demographics.

\begin{tabular}{|c|c|c|c|}
\hline & $\begin{array}{c}\text { Non-haloperidol } \\
(n=56)\end{array}$ & $\begin{array}{l}\text { Haloperidol } \\
\qquad(n=45)\end{array}$ & $p$ \\
\hline Age (years), median (IQR) & $47(28-67)$ & $32(24-43)$ & 0.004 \\
\hline Gender (male) & $34(61)$ & $39(87)$ & 0.004 \\
\hline $\begin{array}{l}\text { Past medical history } \\
\text { Psychiatric } \\
\text { Seizures } \\
\text { Stroke } \\
\text { Traumatic brain injury }\end{array}$ & $\begin{array}{c}6(11) \\
4(7) \\
5(9) \\
2(4)\end{array}$ & $\begin{array}{c}1(2) \\
1(2) \\
0 \\
0\end{array}$ & $\begin{array}{l}0.398 \\
0.652 \\
0.546 \\
0.154\end{array}$ \\
\hline GCS, median (IQR) & $5(3-7)$ & $4(3-7)$ & 0.737 \\
\hline ISS, median (IQR) & $17(9-24)$ & $22(16-27)$ & 0.010 \\
\hline AIS Head, median (IQR) & $3(3-4)$ & $3(3-4)$ & 0.306 \\
\hline $\begin{array}{l}\text { Traumatic brain injury } \\
\text { Epidural hemorrhage } \\
\text { Intracranial hemorrhage } \\
\text { Intraventricular hemorrhage } \\
\text { Subarachnoid hemorrhage } \\
\text { Subdural hemorrhage }\end{array}$ & $\begin{array}{c}3(5) \\
28(50) \\
11(20) \\
39(70) \\
31(55)\end{array}$ & $\begin{array}{l}5(11) \\
19(42) \\
5(11) \\
29(64) \\
19(42)\end{array}$ & $\begin{array}{l}0.284 \\
0.548 \\
0.461 \\
0.671 \\
0.231\end{array}$ \\
\hline Systemic injury & $38(68)$ & $37(82)$ & 0.115 \\
\hline
\end{tabular}

$\mathrm{n}(\%)$ unless otherwise noted

GCS: Glasgow Coma Scale; ISS: Injury Severity Score; AIS: Abbreviated Injury Scale

haloperidol (64\%) compared to IV and enteral (18\%), enteral only (9\%), or intramuscular (4\%).

In evaluating concomitant medications (Table 2), all patients received analgesics throughout the hospital stay. However, the haloperidol group had a significantly longer length of treatment and higher total analgesic dose $(p<0.001)$. Although a majority of patients in both groups received benzodiazepines, significantly more patients in the haloperidol group received benzodiazepines, required higher daily dose, and received longer duration of therapy. The difference in analgesic and benzodiazepine use prior to and following the initiation of haloperidol was compared and no differences were found (data not shown). There was no significant difference in the number of patients who received propofol between the two groups. The haloperidol group had a longer length of treatment $(p=0.033)$, greater average daily dose $(p=0.017)$, and larger total dose $(p=0.003)$. A higher percentage of patients in the haloperidol group did receive quetiapine ( $p<0.001)$ but there was no difference in length of treatment or average daily dose. A majority of patients in both groups received prophylactic antiepileptic therapy (haloperidol $76 \%$ vs. no haloperidol $84 \%, p=0.324$ ) with phenytoin being the most commonly used medication.

\section{Adverse events and complications}

Haloperidol use in acute TBI patients was not associated with an increase in the incidence of complications (Tables 3). All three patients who developed seizures during the study period required intervention. Of the two patients in the haloperidol group, one patient seized on day two of haloperidol therapy with a cumulative haloperidol dose of $20 \mathrm{mg}$ given prior to the seizure. The other patient seized prior to receiving any haloperidol therapy. QT prolongation occurred in eleven patients in the non-haloperidol group versus six patients in the haloperidol group ( $p=0.537)$. The six patients in the haloperidol group received between two to six days of haloperidol therapy before developing $\mathrm{QT}_{\mathrm{c}}$ prolongation. The total dose of haloperidol administered prior to the onset of QT prolongation ranged from 10 to $170 \mathrm{mg}$. None of the patients in the haloperidol group required an intervention for their $\mathrm{QT}_{c}$ prolongation. There was no documented NMS, EPS, or hematologic disturbances in either group.

A subgroup analysis assessing independent risk factors for developing complications was performed in haloperidol patients only $(n=45)$. Of these patients, eight developed complications and 37 did not. Average daily dose was significantly higher in the group who developed complications in a univariate analysis (14 mg vs. $7 \mathrm{mg}$ ) (Table 4). A logistic regression confirmed that an increase in average daily dose of haloperidol was a significant risk factor for developing complications after controlling for age, injury severity, and duration of therapy [OR $1.145,95 \% \mathrm{Cl} 1.021-1.284, \mathrm{p}=0.02$ ].

\section{Clinical outcomes}

Clinical outcomes including LOS and mortality were evaluated (Table 5). While no difference was found in ICU LOS and duration of $\mathrm{MV}$, patients who received haloperidol had a longer hospital LOS but a lower mortality rate.

\section{Discussion}

This is the first study to assess the safety of haloperidol for the treatment of agitation and delirium in acute TBI patients. Low to moderate haloperidol use was not associated with an increased incidence of complications which supports the short-term use of haloperidol in patients with acute TBI.

Although no studies have been conducted to specifically assess haloperidol use in TBI patients, literature is available evaluating its use in general critically ill patients. Girard et al. evaluated the 
Table 2 Concomitant medications.

\begin{tabular}{|c|c|c|c|}
\hline & Non-haloperidol $(n=56)$ & Haloperidol $(n=45)$ & $p$ \\
\hline $\begin{array}{l}\text { Analgesics }^{\dagger}, \mathrm{n}(\%) \\
\text { Length of treatment (days) } \\
\text { Average dose (mg/day) } \\
\text { Total dose }(\mathrm{mg})\end{array}$ & $\begin{array}{c}56(100) \\
9(6-18) \\
25(17-51) \\
252(105-614)\end{array}$ & $\begin{array}{c}45(100) \\
20(13-29) \\
34(18-60) \\
714(365-1208)\end{array}$ & $\begin{array}{c}<0.001 \\
0.192 \\
<0.001\end{array}$ \\
\hline $\begin{array}{l}\text { Benzodiazepines }{ }^{\ddagger}, \mathrm{n}(\%) \\
\text { Length of treatment (days) } \\
\text { Average dose (mg/day) } \\
\text { Total dose (mg) }\end{array}$ & $\begin{array}{c}44(79) \\
3(1-6) \\
8(4-14) \\
24(9-75)\end{array}$ & $\begin{array}{c}44(98) \\
17(8-24) \\
14(6-32) \\
186(77-476)\end{array}$ & $\begin{array}{c}0.005 \\
<0.001 \\
0.034 \\
<0.001\end{array}$ \\
\hline $\begin{array}{l}\text { Quetiapine, } \mathrm{n}(\%) \\
\text { Length of treatment (days } \\
\text { Average dose }(\mathrm{mg} / \text { day) } \\
\text { Total dose }(\mathrm{mg})\end{array}$ & $\begin{array}{c}9(16) \\
7(5-13) \\
96(68-160) \\
625(375-1478)\end{array}$ & $\begin{array}{c}32(71) \\
10(7-20) \\
87(45-177) \\
800(475-3163)\end{array}$ & $\begin{array}{c}<0.001 \\
0.230 \\
0.676 \\
0.34\end{array}$ \\
\hline
\end{tabular}

Median (IQR) unless otherwise noted

${ }^{+}$Analgesics are reported in morphine equivalents.

${ }^{\ddagger}$ Benzodiazepines are reported in midazolam equivalents.

development of complications in patients treated with haloperidol in the ICU compared to ziprasidone and placebo [7]. Thirty-five patients received a median haloperidol dose of $15 \mathrm{mg}$ per day for seven days compared to $10 \mathrm{mg}$ daily for four days in our study. In line with our study, there was no significant difference in serious adverse events, including $\mathrm{QT}_{\mathrm{c}}$ prolongation and NMS.

A retrospective case-control study of 223 critically ill patients showed that $3.6 \%$ (eight patients) developed torsades de pointes secondary to IV haloperidol use [8]. The complication was considered drug related if it developed within 24 hours of haloperidol use. Authors reported that a total daily dose greater than $35 \mathrm{mg}$ was associated with increased risk for QT prolongation. Of six patients who developed QT prolongation in our study, one patient had an event five days following haloperidol administration. While this event may not be related to haloperidol use, we took a conservative approach to include it in our results. Three of the five remaining patients received a total daily dose greater than $30 \mathrm{mg}$ prior to experiencing QT prolongation (40-110 $\mathrm{mg}$ ). This is in line with what has been reported in the literature where QT prolongation is associated with a higher total daily haloperidol dose. None of our patients required an intervention for QT prolongation.

A literature review of the development of NMS in TBI patients treated with haloperidol revealed nine cases [2]. The cumulative dose of haloperidol received prior to the development of NMS was reported in six of these cases, ranging from 10 to $210 \mathrm{mg}$. A majority (five out of six) received $\geq 30 \mathrm{mg}$ per dose. In our study, the cumulative doses ranged from 4 to $563 \mathrm{mg}$ without any evidence of the development of NMS. However, none of our patients received single doses as high as $30 \mathrm{mg}$.

The incidence of seizures with antipsychotic use in TBI patients is unknown. However, haloperidol is one of the few antipsychotic agents available in parenteral formulation and associated with lower seizure risk compared to other antipyschotics [3]. Our study supports this low risk, with only one patient developing a seizure after receiving haloperidol.

Several differences were noted in our study including mortality, hospital LOS, and benzodiazepine use. Although our study is not powered to detect statistical significance in clinical outcomes, a higher mortality was found in patients who did not receive haloperidol compared to those who did. While this finding is similar to what was reported by Milbrandt et al, we suspect this is a coincidental finding due to our small sample size [9]. Additionally, haloperidol is typically given in the later course of a TBI patients' hospitalization in our institution, which may contribute to more haloperidol use in the patients who survived. It should be noted, however, that the difference in baseline severity of injury between the two study groups did not suggest that patients in the no haloperidol group were more likely to expire making the increased mortality an unexpected finding. Ely et al. reported delirium as an independent predictor of longer hospital LOS which supports the result seen in our study [10]. However, the difference in hospital LOS may also be attributed to the higher survival rate in the haloperidol group. This increase in the survival and the hospital LOS may also explain higher benzodiazepine requirements in the haloperidol group.

Due to the retrospective nature of this study, limitations exist which require discussion. The researchers relied on reported laboratory findings and clinical indicators for identification of complications associated with haloperidol administration. Lack of documentation may lead to a low reported incidence of adverse events; however, the documentation does allow capture of clinically relevant adverse events. Additionally, an assessment of concurrent medications for potential QT prolongation was not made when evaluating this adverse event. Another limitation to this study was the relatively small sample size. This sample size may not have been large enough to detect a difference between the groups in the development of complications associated with haloperidol use in TBI patients. A fourth limitation to this study was the lack of a screening tool to differentiate between delirium and agitation in the TBI population. The diagnosis and treatment of delirium and agitation was at the discretion of the managing physician. Therefore, it could not be determined if the increased use of analgesics and benzodiazepines noted in the haloperidol group was due to the lack of early recognition of delirium or if the use of these agents contributed to the development of delirium. Finally, since patients were only followed for the duration of their hospitalization, no assessment could be made regarding the impact of haloperidol use on long-term functional recovery. The limited animal and human studies on long-term functional 
Table 3 Primary outcome-Complications.

\begin{tabular}{|c|c|c|c|}
\hline & $\begin{array}{l}\text { Non-haloperidol } \\
\quad(n=56)\end{array}$ & $\begin{array}{l}\text { Haloperidol } \\
\qquad(n=45)\end{array}$ & $p$ \\
\hline Complication occurred, n (\%) & $12(21)$ & $8(18)$ & 0.803 \\
\hline Seizures, n (\%) & $1(2)$ & $2(4)^{\dagger}$ & 0.537 \\
\hline QT prolongation $^{\ddagger}, \mathrm{n}(\%)$ & $11(20)$ & $6(13)$ & 0.537 \\
\hline
\end{tabular}

Neuroleptic malignant syndrome, extrapyramidal symptoms, or hematologic disturbances did not occur

${ }^{\dagger} A$ seizure occurred on day two of haloperidol therapy after a cumulative dose of $20 \mathrm{mg}$; the other occurred prior to haloperidol administration.

${ }^{\ddagger} Q T$, prolongation occurred in the haloperidol group between days two to six of haloperidol therapy with a cumulative dose ranging from 10 to $170 \mathrm{mg}$; only one patient required an intervention and was in the nonhaloperidol.

Table 4 Haloperidol usage by complications.

\begin{tabular}{|l|c|c|c|} 
& $\begin{array}{c}\text { No Complications } \\
(\mathrm{n}=37)\end{array}$ & $\begin{array}{c}\text { Complications } \\
(\mathrm{n}=8)\end{array}$ & $p$ \\
\hline Hospital day initiated & $10(5-18)$ & $5(3-13)$ & 0.217 \\
\hline Average dose $(\mathrm{mg} / \mathrm{day})$ & $7(5-13)$ & $14(10-27)$ & 0.013 \\
\hline Total dose $(\mathrm{mg})$ & $30(9-73)$ & $75(24-294)$ & 0.084 \\
\hline $\begin{array}{l}\text { Duration of therapy } \\
\text { (days) }\end{array}$ & $3(1-7)$ & $6(2-8)$ & 0.480 \\
\hline
\end{tabular}

Median (IQR) unless otherwise noted recovery after haloperidol administration present conflicting results [11-13].

The use of haloperidol for the treatment of agitation and delirium in patients with acute TBI was not associated with an increased incidence of complications. The complications that did occur in the haloperidol group were associated with higher average daily doses. Prospective studies are needed to further evaluate the relationship between haloperidol and safety outcomes in patients with acute TBI.

Table 5 Clinical outcomes.

\begin{tabular}{|c|c|c|c|}
\hline & $\begin{array}{l}\text { Non-haloperidol } \\
\qquad(n=56)\end{array}$ & $\begin{array}{l}\text { Haloperidol } \\
\quad(n=45)\end{array}$ & $p$ \\
\hline ICU LOS (days) & $7(4-11)$ & $7(6-11)$ & 0.349 \\
\hline Hospital LOS (days) & $11(7-22)$ & $22(15-33)$ & $<0.001$ \\
\hline $\begin{array}{l}\text { Duration of MV } \\
\text { (days) }\end{array}$ & $7(2-12)$ & $6(4-9)$ & 0.888 \\
\hline Mortality ${ }^{\dagger}, \mathrm{n}(\%)$ & $14(25)$ & $1(2)$ & $<0.001$ \\
\hline
\end{tabular}

Median (IQR) unless otherwise noted

ICU: Intensive Care Unit; LOS: Length of Stay; MV: Mechanical Ventilation +Withdrawal of 11 in the non-haloperidol group and one in the haloperidol group 


\section{References}

1 Girard TD, Pandharipande PP, Ely EW (2008) Delirium in the intensive care unit. Crit Care 12: S3.

2 Bellamy CJ, Kane-Gill SL, Falcione BA, Seybert AL (2009) Neuroleptic malignant syndrome in traumatic brain injury patients treated with haloperidol. J Trauma 66: 954-958.

3 Crimson L, Argo TR, Buckley PF (2008) Schizophrenia. In: DiPiro JT, Talbert RL, Yee GC, Matzke GR, Wells BG, et al. (Eds.) Pharmacotherapy: A Pathophysiologic Approach. McGraw-Hill, New York.

4 Heegaard W, Biros M (2007) Traumatic brain injury. Emerg Med Clin N Am 25: 655-678.

5 MacLaren R, Sullivan PW (2005) Pharmacoeconomic modeling of lorazepam, midazolam, and propofol for continuous sedation in critically ill patients. Pharmacotherapy $25: 1319-1328$.

6 Zemrak WR, Kenna GA (2008) Association of antipsychotic and antidepressant drugs with Q-T interval prolongation. Am J Health Syst Pharm 65: 1029-1038.

7 Girard TD, Pandharipande PP, Carson SS, Schmidt GA, Wright PE, et al. (2010) Feasibility, efficacy, and safety of antipsychotics for intensive care unit delirium: the MIND randomized, placebo-controlled trial. Crit Care Med 38: 428-437.

8 Sharma ND, Rosman HS, Padhi ID, Tisdale JE (1998) Torsades de Pointes associated with intravenous haloperidol in critically ill patients. Am J Cardiol 81: 238-240.

9 Milbrandt EB, Kersten A, Kong L, Weissfeld LA, Clermont G, et al. (2005) Haloperidol use is associated with lower hospital mortality in mechanically ventilated patients. Crit Care Med 33: 226-229.

10 Ely EW, Shintani A, Truman B, Speroff T, Gordon SM, et al. (2004) Delirium as a predictor of mortality in mechanically ventilated patients in the intensive care unit. JAMA 291: 1753-1762.

11 Kline AE, Massucci JL, Zafonte RD, Dixon E, DeFeo JR, et al. (2007) Differential effects of single versus multiple administrations of haloperidol and risperidone on functional outcome after experimental brain trauma. Crit Care Med 35: 919-924.

12 Rao N, Jellinek HM, Woolston DC (1985) Agitation in closed head injury: haloperidol effects on rehabilitation outcome. Arch Phys Med Rehabil 66: 30-34.

13 Wilson MS, Gibson CJ, Hamm RJ (2003) Haloperidol, but not olanzapine, impairs cognitive performance after traumatic brain injury in rats. Am J Phys Med Rehabil 82: 871-879. 